\title{
Variability of ant community composition in cork oak woodlands across the Mediterranean region: implications for forest management
}

\author{
Marcello Verdinelli ${ }^{(1)}$, \\ Salah Eddine Bakkali Yakhlef ${ }^{(2)}$, \\ Carlo Simone Cossu ${ }^{(1)}$, \\ Oriana Pilia ${ }^{(1)}$, \\ Roberto Mannu ${ }^{(1)}$
}

\begin{abstract}
We evaluated the potential use of ants as a powerful tool for environmental monitoring, together with the applicability of the functional group approach as an alternative method for studying ant communities in cork oak woodlands. Variations in ant community composition, diversity and functional groups were studied in two cork oak forested sites across the Mediterranean region. Ants were sampled using pitfall traps placed along linear transects at 12 sites located in the main cork districts of Italy and Morocco (Gallura in Sardinia, and Maâmora, east of Rabat). A total of 13,501 specimens were collected, belonging to 38 species (five shared species). A distinct separation in the NMDS plots between Gallura and Maâmora ant assemblages was clearly visible. Ant species composition was widely different between the two districts and significant differences were detected within the Gallura district at the species level. Opportunist species were well represented in Gallura (about $27 \%$ of average BrayCurtis similarity) as well as cryptic species (over 23\%). In the Maâmora forest, generalized Myrmicinae, hot climate specialists and opportunists contributed equally to the average similarity (together about 53\%). Multi-scale ant diversity showed that the true turnover was higher in Gallura than in Maâmora. These findings support the idea that the functional group approach, rather than species diversity per se, could be considered as a valuable tool to detect the response of the ant community to environmental changes in Mediterranean cork oak woodlands. Using ants as bioindicators could help not only in detecting early warning signs of habitat disturbance, but also in defining a useful management strategy to increase the resilience of agroforestry systems under future global change scenarios.
\end{abstract}

Keywords: Cork Oak, Forest Management, Ants, Bioindicators

wood pastures in Europe. Cork oak woodlands have historically been subjected to intense disturbances, with a greater threat of deforestation in recent times (Aronson et al. 2009). Inadequate management and land overuse are the main triggers of several dynamic interactions that compromise the ecology and conservation of cork oak woodlands (Aronson et al. 2009, Bugalho et al. 2011). In the decades to come, the combined pressure of climatic change and anthropogenic impacts will likely exacerbate the effects of pests and pathogens, which in turn will increase the vulnerability
(1) Istituto per lo Studio degli Ecosistemi, CNR, Traversa La Crucca 3, 07100 Sassari (Italy); (2) Division de l'Enseignement Supérieur et de la la Recherche et du Développement, Direction de l'Enseignement, de la Formation et de la Recherche, Station D'bagh - Avenue Hassan II, B.P. 607 Rabat (Morocco)

@ Marcello Verdinelli (m.verdinelli@ise.cnr.it)

Received: Dec 19, 2016 - Accepted: May 12, 2017

Citation: Verdinelli M, Yakhlef SEB, Cossu CS, Pilia O, Mannu R (2017). Variability of ant community composition in cork oak woodlands across the Mediterranean region: implications for forest management. iForest 10: 707-714. - doi: 10.3832/ifor2321-010 [online 2017-07-27]

Communicated by: Massimo Faccoli of cork oak landscapes, thus accelerating tree mortality and limiting the natural regeneration.

Playing a key role in biodiversity, with a variety of specific responses to environmental stressors, macroinvertebrates have been extensively used as biological indicators in a vast range of habitats (Gerlach et al. 2013). The role of ants as environmental indicators is thus becoming more important in assessing the ecological health of terrestrial ecosystems, mostly because of their high diversity and functional importance (Andersen et al. 2002, Andersen \& Majer 2004, Ellison 2012, Fisher et al. 2014). Ants are well represented in almost all terrestrial habitats because of a wide range of thermal niches and their ability to cope in varying environmental conditions. Most studies focusing on the use of ants as bioindicators have been conducted in Australia, and North and South America, whereas less attention has been devoted to understanding the anthropogenic impact on European ant communities (Castracani \& Mori 2006, Ottonetti et al. 2006, Castracani et al. 2010, Azcarate \& Peco 2012, Satta et al. 2012). The analysis of ant community structures in relation to habitat stress or disturbance could be a valuable tool to detect early environmental changes in Me- 
diterranean habitats (Cammell et al. 1996, Gómez et al. 2003, Castracani et al. 2010).

Species richness and other traditional diversity measures have been commonly used in several ecological studies concerning ants as model organisms (Castracani \& Mori 2006, Graham et al. 2009). Recently, there has been considerable interest in the use of a complementary approach based on functional groups to predict ant spatial patterns in disturbed landscapes. This approach has been used in Australia and North America to reduce the complexity of ant taxonomy, and could also be exploited as a reliable model for examining the ant community structure and its relationship with land use (Andersen 1995, Bestelmeyer \& Wiens 1996, Andersen et al. 2002). Since ant assemblages do not always follow a regular trend in response to environmental stress and disturbance, there is an urgent need for more studies focusing on species patterns, functional groups, diversity and dominance in order to provide a more accurate predictive understanding of the mechanisms that influence ant distributions in cork oak woodlands in warm-temperate regions.

In this study, we compared ant communities from cork oak woodlands in the main cork districts of Italy (Gallura, Sardinia) and Morocco (Maâmora forest), which represent two striking examples of contrasting forest-management models.

The Gallura cork oak district, with an area of about 39,000 hectares, is a semi-natural system in which agricultural and pastoral activities coexist with the cork oak industry. Depending on the prevailing land use (cereal grains for fodder, grazing, hunting, cork production), the structure of the Q. suber forests varies across the district. The forest ownership is fragmented and cork production, which is mainly located in rural marginal areas, is often considered as a secondary source of income. In parts of the Gallura district, there is a lack of natural regeneration (Rossetti \& Bagella 2014). Consequently, much effort and public funds have been devoted to improving woodland management practices.

The Maâmora forest is considered to be the largest existing managed cork oak woodland in the world, and represents a paradigmatic example of a forest subject to a dramatic human pressure due to overgrazing and intensive cattle breeding (Aronson et al. 2009). The cork oak forest, originally encompassing an area of 300,000 ha (Boudy 1950), has now been reduced to less than 70,000 ha (Bugalho et al. 2011). As in most other western Mediterranean countries, there is almost no natural regeneration in the entire Maâmora forest, and attempts have been made to reduce anthropogenic pressures through projects that encourage sustainable forest management (Besacier \& Gallo Granizo 2014). Artificial reforestation (with eucalyptus, pine and acacia) is largely practiced over the entire area, although much effort has been devoted to achieving a better cork oak protection and regeneration in recent decades (Aronson et al. 2009). In addition to their ecological role, cork oak woodlands are considered to be very important multipurpose systems in Morocco due to the wide range of goods and services they produce (wood products, cork, aromatic and medicinal plants, fodder for livestock, ecotourism). The dominance of cistus and asphodel, the decline in the abundance of plant and animal species, accompanied by the deterioration in the forest structure and the absence of natural regeneration, represent signs of land degradation in Maâmora

Tab. 1 - Main characteristics of the cork oak districts analyzed in this study.

\begin{tabular}{|c|c|c|c|c|c|}
\hline District & Site & $\begin{array}{l}\text { Geographic } \\
\text { Coordinates }\end{array}$ & $\begin{array}{l}\text { Elevation } \\
\text { (m a.s.l.) }\end{array}$ & $\begin{array}{l}\text { Canopy } \\
\text { cover (\%) }\end{array}$ & Main land use \\
\hline \multirow[t]{6}{*}{ Italy } & G1 & $\begin{array}{r}40.7162 \mathrm{~N} \\
9.0480 \mathrm{E}\end{array}$ & 202 & 33.22 & Grazing, cork production \\
\hline & G2 & $\begin{array}{r}40.7456 \mathrm{~N} \\
9.0912 \mathrm{E}\end{array}$ & 221 & 58.35 & $\begin{array}{l}\text { Grain for fodder, cork } \\
\text { production }\end{array}$ \\
\hline & G3 & $\begin{array}{r}40.7737 \mathrm{~N} \\
9.0958 \mathrm{E}\end{array}$ & 207 & 85.31 & Cork production \\
\hline & G4 & $\begin{array}{r}40.7803 \mathrm{~N} \\
9.1143 \mathrm{E}\end{array}$ & 226 & 65.19 & Cork production \\
\hline & G5 & $\begin{array}{r}40.7883 \mathrm{~N} \\
9.1831 \mathrm{E}\end{array}$ & 259 & 60.37 & Grazing, cork production \\
\hline & G6 & $\begin{array}{c}40.7927 \mathrm{~N} \\
9.2294 \mathrm{E}\end{array}$ & 330 & 46.68 & $\begin{array}{l}\text { Grain for fodder, cork } \\
\text { production }\end{array}$ \\
\hline \multirow[t]{6}{*}{ Morocco } & M1 & $\begin{array}{r}34.2072 \mathrm{~N} \\
6.5657 \mathrm{~W}\end{array}$ & 94 & 40.66 & $\begin{array}{l}\text { No cork extraction, no } \\
\text { grazing }\end{array}$ \\
\hline & $M 2$ & $\begin{array}{r}34.1841 \mathrm{~N} \\
6.6175 \mathrm{~W}\end{array}$ & 63 & 24.31 & $\begin{array}{l}\text { No cork extraction, no } \\
\text { grazing }\end{array}$ \\
\hline & M3 & $\begin{array}{r}34.0286 \mathrm{~N} \\
6.5538 \mathrm{~W}\end{array}$ & 168 & 50.70 & Cork production \\
\hline & M4 & $\begin{array}{r}34.0475 \mathrm{~N} \\
6.6008 \mathrm{~W}\end{array}$ & 149 & 34.86 & Cork production \\
\hline & M5 & $\begin{array}{r}34.0862 \mathrm{~N} \\
6.6321 \mathrm{~W}\end{array}$ & 117 & 51.21 & Cork production, grazing \\
\hline & M6 & $\begin{array}{r}34.1304 \mathrm{~N} \\
6.5917 \mathrm{~W}\end{array}$ & 102 & 38.35 & Cork production, grazing \\
\hline
\end{tabular}

(Nafaa 2002).

The aim of our work was to compare the ant assemblages between the cork oak woodlands of the two sites in Morocco and Italy; to study how the diversity and faunal composition varied at different spatial scales; and how the functional group scheme could be adapted to Mediterranean ant assemblages.

\section{Materials and methods}

\section{Study areas and ant sampling}

The study was conducted in the main cork oak districts of Gallura (Sardinia, Italy) and Maâmora (Morocco). The Gallura cork oak district is located in a typical Mediterranean landscape in the north of Sardinia, at an altitude of 50-600 $\mathrm{m}$ a.s.l. The climate is Mediterranean, with mild winters, hot and dry summers; the rainfall distribution follows a typical Mediterranean pattern with a long dry season during the warmer months and a greater concentration in late autumn and early spring (average annual temperature $13.4^{\circ} \mathrm{C}$, average annual precipitation $785 \mathrm{~mm}$ ).

In the Gallura area, soils are Eutric Leptosols (Costantini et al. 2012) according to the IUSS Working Group (2007). The understory vegetation is mainly composed of rockrose (Cistus monspeliensis Linnaeus, 1753 and Cistus salvifolius Linnaeus, 1753), broom [Calicotome spinosa (Linnaeus, 1753) Link, 1822, Cytisus villosus Pourret, 1788], lavender (Lavandula stoechas Linnaeus, 1753) and asphodel (Asphodelus ramosus Linnaeus, 1753).

The Maâmora forest is located within the two regions of Gharb-Chrarda-Béni Hssen and Rabat-Salé-Zemmour-Zaer in the north of Morocco (elevation 7-290 m a.s.l.). The climate ranges from sub-humid warm winters near the Atlantic cost to semiarid and more moderate winters in the central and eastern regions (mean annual temperature $20{ }^{\circ} \mathrm{C}$, mean annual precipitation $400 \mathrm{~mm}$ ).

Maâmora soils are classified as Chromic Luvisols (Dewitte et al. 2013). The natural understory vegetation is extremely rich (Aafi et al. 2005) and includes the Mediterranean palm (Chamaerops humilis Linnaeus, 1753), rockrose (C. salvifolius), broom (C. arboreus Linnaeus, 1753 and Genista linifolia Linnaeus, 1753), giant fennel (Ferula communis Linnaeus, 1753), European frostweed [Tuberaria guttata (Linnaeus, 1753) Fourreau, 1868], thatching grass [Hyparrhenia hirta (Linnaeus, 1753) Stapf, 1919], lavender (L. stoechas), narrow-leaved lupin (Lupinus angustifolius Linnaeus, 1753) and rabbitfoot clover (Trifolium arvense Linnaeus, 1753). Pyrus mamorensis Trabut, 1916 is the only endemic tree in Maâmora forest.

Twelve 1-ha sites were randomly selected across an area of approximately 15,000 and 20,000 ha for Gallura and Maâmora, respectively (see Tab. 1 for more information). In order to partially extend the vegetational information on each district, the canopy cover (i.e., the vertical projection of 
tree crowns on the forest floor) was estimated for each site using Google Earth Pro (http://earth.google.com). All high resolution digital images $(4800 \times 2718$ pixels $)$ were processed to extract the canopy information from satellite images using the open-source GIMP v. 2.8 software (http:// www.gimp.org). The background represented by the ground, the bare soil and the understory vegetation was removed and digital images were turned into black-andwhite. Forest canopy cover was then estimated as the percentage of black pixels in the binary images (Stewart et al. 2007).

At each site, we buried eight pitfall traps (polypropylene cups, $7 \times 11.8 \mathrm{~cm}$, diameter $x$ depth) partially filled with a solution of water and monopropylene glycol $(5 / 1, v / v)$, and spaced approximately $10-15 \mathrm{~m}$ from each other along a linear transect. Grounddwelling ants were collected from 96 pitfall traps ( 2 cork oak districts $\times 6$ transects $\times 8$ traps $=96$ traps). Pitfall-traps were checked and emptied once a month from April to October 2010, in order to take into account the different levels of catchability of the ant species throughout the cork oak vegetation season. The traps were operated for one week each month. At the end of each sampling week, all traps were replaced with identical traps with tight-fitting lids. In the following month, the covers were removed and the traps were reactivated. The "digging-in effect" and the disturbance of the surface around the traps were thus strongly reduced.

Specimens were collected and preserved in $70 \%$ ethanol, then taken to the laboratory for identification to the lowest taxonomic level possible. When necessary, specimens were compared with ant material deposited in the following institutions: Museo Civico di Storia Naturale, Genova (MCSN); Dipartimento di Valorizzazione e Protezione delle Risorse Agroforestali - Entomologia e Zoologia applicate all'ambiente "Carlo Vidano", Torino (Italy) (DiVaPRA); Dipartimento di Scienze e Tecnologie Agroambientali - Istituto di Entomologia "G. Grandi", Bologna (Italy) (DiSTA); Naturhistorisches Museum, Basel (Switzerland) (NMB); Dipartimento di Biologia Animale ed Ecologia dell'Università, Cagliari (Italy) (DiBAE); Dipartimento di Agraria dell'Università, Sezione di Patologia Vegetale ed Entomologia, Sassari (SPaVE). Only the worker caste was considered in the analysis of counts and the nomenclature was based on AntWiki (2016).

The comparison between the ant assemblages of the two districts was based on a species and functional group approach. Ants were sorted into morphospecies and all specimens were assigned to different functional groups: Subordinate Camponotini (SC), Hot-climate Specialists (HC), Coldclimate Specialists (CC), Cryptic Species (Cr), Opportunists (Op), and Generalized Myrmicinae (GM - Andersen 1995). Although this classification still suffers from problems of interpretation, it has also gained acceptance in the Mediterranean region (Gómez et al. 2003, Ottonetti et al. 2006, Azcarate \& Peco 2012).

\section{Statistical analyses}

Ant species richness (S) was measured as the observed number of species per district, site and trap. Species richness at different scales was analysed by a two-tailed t-test to examine significant differences between the two districts using Statgraphics Plus ${ }^{\oplus}$ ver. 5.1 (Statistical Graphics Corp. 2001). The Chao-2 non-parametric estimator (Colwell 2006) of asymptotic richness was estimated for each district, and species accumulation curves (999 permutations) were generated to evaluate the adequacy of the sampling using EstimateS ver. 9.1.0 (Colwell 2006).

The counts of workers from each single trap retrieved each month were reduced to the presence/absence to down-weigh the contributions of quantitatively dominant species and to avoid the effects of mass catches due to any traps that might have been accidentally placed close to nest entrances or foraging trails. In order to exclude capture variations due to the seasons, all incidence data were pooled over the sampling period. Statistical analyses were therefore based on the frequency of each species, i.e., the number of pitfall traps per site where each species was collected throughout the entire survey.

Non-metric multidimensional scaling (NMDS), based on Bray-Curtis dissimilarity measures, was used to examine the variation in the ant community composition between the two districts.

The non-parametric analysis of similarities (ANOSIM) was performed in order to test for any differences in ant assemblages among sites, within and between districts. The species/functional groups contributing the most to dissimilarities among sites and districts were identified using the similarity percentage (SIMPER) routine (Warwick et al. 1990). Multivariate analyses were run using the Primer ver. 6 package (Clarke \& Gorley 2006). For each forest district, BrayCurtis indices of dissimilarity $\left(d_{B C}\right)$ were also computed using the occurrence-based matching components. Dissimilarities were portioned into the balanced variation component $\left(\mathrm{d}_{\mathrm{BC}-\mathrm{bal}}\right)$ and gradient component $\left(\mathrm{d}_{\mathrm{BC}-\mathrm{gra}}\right)$, representing the degree of substitution by a species from site to site (i.e., turnover), and species nestedness in incidence-based patterns, respectively (Baselga 2013).

Analyses were performed following Baselga (2013) using the "betapart" package (Baselga \& Orme 2012) in R ( $R$ Development Core Team 2011). Finally, beta diversity was estimated by computing the average dissimilarities, separately for Bray-Curtis dissimilarities and its components, in ant assemblages among all pairs from sites of each cork oak district (Anderson et al. 2011).

\section{Results}

The pitfall traps caught a total of 13,501 ant workers. Throughout the entire survey, 25 and 18 species were recorded in Gallura and Maâmora forests, respectively. The 38 species recorded in this study were assigned to six functional groups (Tab. 2). The sample-based rarefaction curves were close to their plateau, thus indicating an adequate sampling in terms of estimating the number of ant species (Fig. 1). The Chao-2 estimators showed that the species richness at the district scale was higher in Gallura (mean \pm SD: $26.12 \pm 1.77$ ) than in Maâmora (mean \pm SD: $18.00 \pm 0.04$ ). In addition, the richness was slightly underestimated for Gallura, probably as a consequence of a higher number of singletons and doubletons. In contrast, species richness per pitfall trap was over two times higher in Maâmora than in Gallura (16.02 \pm 1.68 vs. $7.25 \pm 2.03 ; t=16.81, d f=47, p<$ 0.01). Significant differences were also found at the site scale with a higher species richness in Maâmora (17.17 \pm 0.41 vs. $14.5 \pm 2.07 ; t=3.11, d f=5, p=0.03)$.

Five species were shared between Gallura and Maâmora (C. lateralis, C. truncatus, C. scutellaris, P. pallidula, and T. simrothi), contributing to $27.4 \%$ of the total number of occurrences. Summarizing the occurrences in the two districts, the most frequent species were C. scutellaris (7.9\%), T. simrothi (5.8\%), C. lateralis (5.5\%), A. senilis (4.2\%), A. theryi ( $4.2 \%)$, C. truncatus (4.2\%), C. auberti (4.2\%), and A. spinosa (4.1\%), thus representing about $40 \%$ of the total number.

As a consequence, a distinct and reliable separation in the NMDS plots between assemblages in Gallura and Maâmora was clearly visible at the species level. In addition, a good ordination was also obtained at the functional group level, as shown by the low stress value obtained (Fig. 2). However, groupings of site data were not distinguishable within the Maâmora district, where samples overlapped. One-way ANOSIM was performed separately in order to test for differences in ant assemblages between and within each district, thus providing an indirect estimation of beta diversity. The analysis confirmed the differences between the districts in catch composition (based on species and functional groups) showed by the ordination plot. Based on species, ant assemblages differed widely (district as factor: $R=0.99, p<0.001$; site as factor: $R=0.58, p<0.001)$. However, ant assemblages did not vary within Maâmora $(R=0.01, p<0.03)$, whereas differences were detected among the sites in Gallura $(R=0.27, p<0.001)$. These differences were also detected with functional groups (district as factor: $\mathrm{R}=0.32, \mathrm{p}<0.001$; site as factor: $R=0.20, p<0.001$ ). Ant functional groups did not differ among sites either in Gallura $(R=0.03, p<0.03)$ or in Maâmora $(R=0.01, p<0.20)$.

A SIMPER test, performed by comparing all pairs of sites and using the trap as the spatial scale, identified four taxa as typify- 
Tab. 2 - List of ants collected, functional group (FG) assigned, number of workers and species richness at the site scale for Gallura (G1-G6 sites) and Maâmora (M1-M6 sites). Ant functional groups: Subordinate Camponotini (SC), Hot-climate Specialists (HC), Coldclimate Specialists (CC), Cryptic Species (Cr), Opportunists (Op) and Generalized Myrmicinae (GM). Following Gómez et al. (2003), A. subterranea was put in the Cryptic Species group.

\begin{tabular}{|c|c|c|c|c|c|c|c|c|c|c|c|c|c|}
\hline \multirow{2}{*}{ Species } & \multirow{2}{*}{ FG } & \multicolumn{6}{|c|}{ Gallura } & \multicolumn{6}{|c|}{ Maâmora } \\
\hline & & G1 & G2 & G3 & G4 & G5 & G6 & M1 & M2 & M3 & M4 & M5 & M6 \\
\hline Aphaenogaster senilis Mayr, 1853 & Op & 0 & 0 & 0 & 0 & 0 & 0 & 62 & 31 & 148 & 137 & 117 & 154 \\
\hline Aphaenogaster spinosa Emery, 1878 & Op & 66 & 205 & 205 & 79 & 351 & 691 & 0 & 0 & 0 & 0 & 0 & 0 \\
\hline Aphaenogaster subterranea (Latreille, 1798) & $\mathrm{Cr}$ & 4 & 7 & 157 & 213 & 0 & 3 & 0 & 0 & 0 & 0 & 0 & 0 \\
\hline Aphaenogaster theryi Santschi, 1923 & Op & 0 & 0 & 0 & 0 & 0 & 0 & 89 & 77 & 98 & 65 & 93 & 75 \\
\hline Camponotus aethiops (Latreille, 1798) & SC & 21 & 14 & 16 & 5 & 28 & 12 & 0 & 0 & 0 & 0 & 0 & 0 \\
\hline Camponotus gestroi Emery, 1878 & SC & 2 & 0 & 0 & 0 & 1 & 0 & 0 & 0 & 0 & 0 & 0 & 0 \\
\hline Camponotus lateralis (Olivier, 1792) & SC & 1 & 6 & 5 & 7 & 1 & 7 & 85 & 41 & 125 & 70 & 80 & 67 \\
\hline Camponotus piceus (Leach, 1825) & SC & 0 & 1 & 0 & 1 & 0 & 0 & 0 & 0 & 0 & 0 & 0 & 0 \\
\hline Camponotus serotinus Cagniant, 1996 & SC & 0 & 0 & 0 & 0 & 0 & 0 & 52 & 52 & 96 & 84 & 97 & 80 \\
\hline Cataglyphis viatica (Fabricius, 1787) & $\mathrm{HC}$ & 0 & 0 & 0 & 0 & 0 & 0 & 94 & 77 & 87 & 75 & 74 & 128 \\
\hline Colobopsis truncata (Spinola, 1808) & SC & 4 & 0 & 0 & 0 & 1 & 0 & 81 & 35 & 101 & 44 & 84 & 84 \\
\hline Crematogaster auberti Emery, 1869 & GM & 0 & 0 & 0 & 0 & 0 & 0 & 126 & 97 & 130 & 62 & 124 & 144 \\
\hline Crematogaster scutellaris (Olivier, 1792) & GM & 129 & 34 & 143 & 56 & 47 & 126 & 99 & 37 & 129 & 91 & 86 & 133 \\
\hline Hypoponera eduardi (Forel, 1894) & $\mathrm{Cr}$ & 0 & 35 & 0 & 0 & 0 & 1 & 0 & 0 & 0 & 0 & 0 & 0 \\
\hline Lasius lasioides (Emery, 1869) & $\mathrm{CC}$ & 2 & 0 & 0 & 0 & 0 & 0 & 0 & 0 & 0 & 0 & 0 & 0 \\
\hline Lasius niger (Linnaeus, 1758) & $\mathrm{CC}$ & 0 & 5 & 0 & 0 & 20 & 0 & 0 & 0 & 0 & 0 & 0 & 0 \\
\hline Lasius paralienus Seifert, 1992 & $\mathrm{CC}$ & 0 & 17 & 0 & 5 & 6 & 0 & 0 & 0 & 0 & 0 & 0 & 0 \\
\hline Messor capitatus (Latreille, 1798) & $\mathrm{HC}$ & 0 & 0 & 1 & 0 & 0 & 0 & 0 & 0 & 0 & 0 & 0 & 0 \\
\hline Messor marocanus Santschi, 1927 & $\mathrm{HC}$ & 0 & 0 & 0 & 0 & 0 & 0 & 82 & 60 & 118 & 82 & 73 & 71 \\
\hline Messor minor (André, 1883) & $\mathrm{HC}$ & 0 & 5 & 5 & 0 & 466 & 0 & 0 & 0 & 0 & 0 & 0 & 0 \\
\hline Messor wasmanni Krausse, 1910 & $\mathrm{HC}$ & 3 & 1 & 0 & 0 & 20 & 573 & 0 & 0 & 0 & 0 & 0 & 0 \\
\hline Monomorium subopacum (Smith, Frederick, 1858) & GM & 0 & 0 & 0 & 0 & 0 & 0 & 58 & 59 & 77 & 72 & 100 & 77 \\
\hline Oxyopomyrmex saulcyi Emery, 1889 & $\mathrm{HC}$ & 0 & 0 & 0 & 0 & 0 & 0 & 73 & 45 & 117 & 66 & 48 & 80 \\
\hline Pheidole pallidula (Nylander, 1849) & GM & 0 & 0 & 0 & 0 & 33 & 0 & 74 & 57 & 81 & 69 & 80 & 51 \\
\hline Plagiolepis pygmaea (Latreille, 1798) & $\mathrm{Cr}$ & 6 & 10 & 13 & 5 & 22 & 30 & 0 & 0 & 0 & 0 & 0 & 0 \\
\hline Plagiolepis schmitzii Forel, 1895 & $\mathrm{Cr}$ & 0 & 0 & 0 & 0 & 0 & 0 & 74 & 45 & 75 & 65 & 68 & 63 \\
\hline Plagiolepis sp. Mayr, 1861 & $\mathrm{Cr}$ & 1 & 0 & 0 & 0 & 0 & 0 & 0 & 0 & 0 & 0 & 0 & 0 \\
\hline Ponera coarctata (Latreille, 1802) & $\mathrm{Cr}$ & 2 & 0 & 0 & 1 & 0 & 1 & 0 & 0 & 0 & 0 & 0 & 0 \\
\hline Solenopsis fugax (Latreille, 1798) & $\mathrm{Cr}$ & 72 & 42 & 55 & 24 & 15 & 42 & 0 & 0 & 0 & 0 & 0 & 0 \\
\hline Stenamma striatulum Emery, 1895 & $\mathrm{CC}$ & 0 & 0 & 0 & 2 & 0 & 0 & 0 & 0 & 0 & 0 & 0 & 0 \\
\hline Tapinoma simrothi Krausse, 1911 & Op & 84 & 9 & 0 & 1 & 174 & 10 & 77 & 58 & 107 & 150 & 106 & 65 \\
\hline Temnothorax mediterraneus (Ward et al. 2015) & $\mathrm{CC}$ & 0 & 8 & 0 & 0 & 0 & 2 & 0 & 0 & 0 & 0 & 0 & 0 \\
\hline Temnothorax marocana (Santschi, 1909) & $\mathrm{CC}$ & 0 & 0 & 0 & 0 & 0 & 0 & 93 & 32 & 97 & 82 & 70 & 70 \\
\hline Temnothorax mimeuri (Cagniant, 1997) & $\mathrm{CC}$ & 0 & 0 & 0 & 0 & 0 & 0 & 71 & 42 & 57 & 60 & 52 & 57 \\
\hline Temnothorax specularis (Emery, 1916) & $\mathrm{CC}$ & 6 & 1 & 5 & 2 & 0 & 2 & 0 & 0 & 0 & 0 & 0 & 0 \\
\hline Temnothorax sp. Mayr, 1861 & $\mathrm{CC}$ & 0 & 0 & 0 & 0 & 0 & 0 & 0 & 1 & 0 & 0 & 0 & 0 \\
\hline Tetramorium brevicorne Bondroit, 1918 & Op & 165 & 82 & 35 & 1 & 210 & 154 & 0 & 0 & 0 & 0 & 0 & 0 \\
\hline Tetramorium forte Forel, 1904 & Op & 0 & 0 & 0 & 0 & 0 & 0 & 86 & 84 & 145 & 64 & 96 & 81 \\
\hline Species richness (S) & - & 16 & 17 & 11 & 14 & 15 & 14 & 17 & 18 & 17 & 17 & 17 & 17 \\
\hline
\end{tabular}

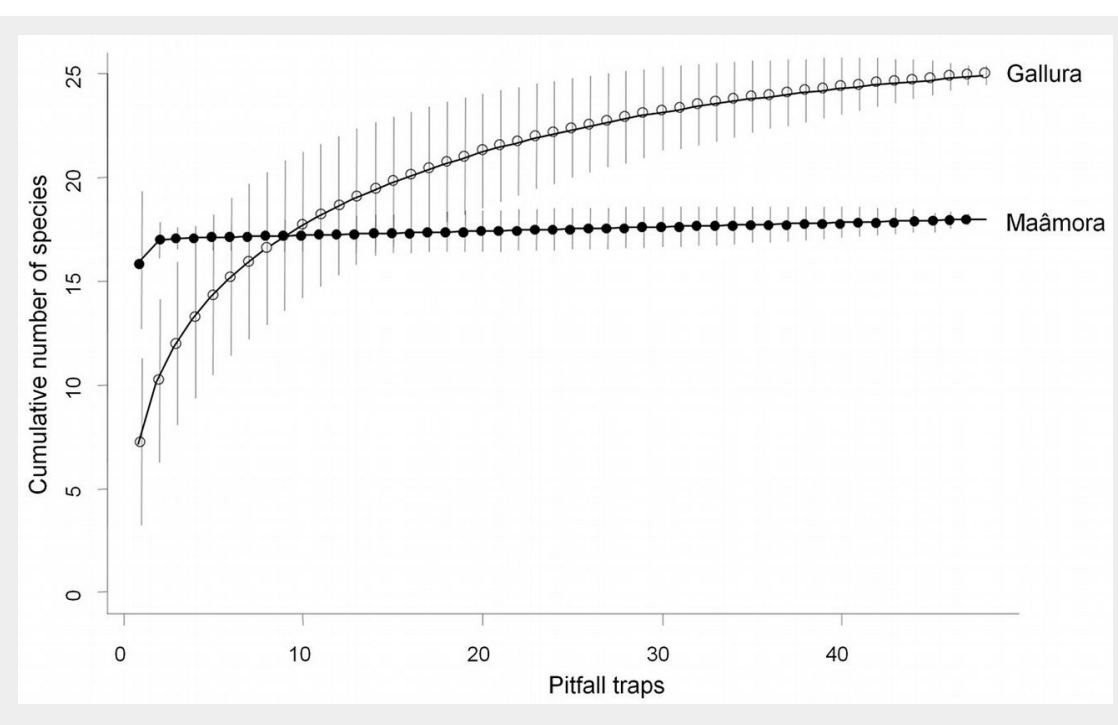

Fig. 1 - Ant species accumulation curves (bars: $95 \%$ confidence interval) in cork oak woodlands in Italy (Gallura) and Morocco (Maâmora). 
ing species of the Gallura district. A. spinosa, C. scutellaris (both species generally linked to arboreal habitats and open woodlands with a more complex structure), $T$. brevicorne, C. aethiops and Solenopsis fugax gave a cumulative contribution of $77.5 \%$ to the average Bray-Curtis similarity (58.2), i.e., the measure of variation in ant assemblages within the district. A similar result was obtained using the site as the spatial scale, however, the relative contribution of A. spinosa to the average similarity decreased from $22.2 \%$ (trap as spatial scale) to 17.9\%. In Maâmora, the Bray-Curtis similarity was high (over 90\%) and no group of typifying species was clearly identified (thirteen species contributed to $78.4 \%$ of the total similarity in the Maâmora district). Nevertheless, C. auberti, A. senilis, A. theryi, and $C$. scutellaris (species linked to open woodlands and grasslands) were the species that contributed most to the average similarity at the trap scale. The same pattern was observed at the site scale.

In terms of functional groups and traps, Opportunists were well represented in Gallura (about $27 \%$ average Bray-Curtis similarity) as well as Cryptic Species (over 23\%). In Maâmora forest, Generalized Myrmicinae, Hot Climate Specialists, Opportunists and Subordinate Camponotini contributed equally to the average similarity (together about $70 \%$ ), and the relative contribution of Cold Climate Specialists and Cryptic Species was very low. At the site scale, the relative importance of Opportunists decreased in Gallura, whereas no differences were detected for Maâmora in terms of the different scales.

Tab. 3 lists the percentage contribution of each district to the overall Bray-Curtis dissimilarity in terms of traps and sites (a measure of the differences among ant assemblages). The average dissimilarity at both spatial scales was low, and the assemblages of the two cork oak districts diverged above all in terms of the contribution of Hot-climate Specialists and Cold-climate Specialists. Tab. 4 reports the partition of beta diversity into the two separate components of spatial turnover and nestedness. In Gallura the turnover $\left(\mathrm{d}_{\mathrm{BC} \text {-bal }}\right)$ was higher than in Maâmora. However, using functional groups, the turnover decreased from fine to coarse spatial scales. Conversely, in Maâmora, beta diversity at the trap scale was primarily due to the $d_{B c \text { gra }}$ component (i.e., nestedness) considering species and functional groups, whereas at the site scale, nestedness increased dramatically from species to functional groups.

\section{Discussion}

The cork oak woodlands of Gallura and Maâmora could be considered as similar agro-forestry systems in terms of characteristics, land uses and management. They are both located in the Mediterranean region and are predominantly used for cork production and livestock grazing.

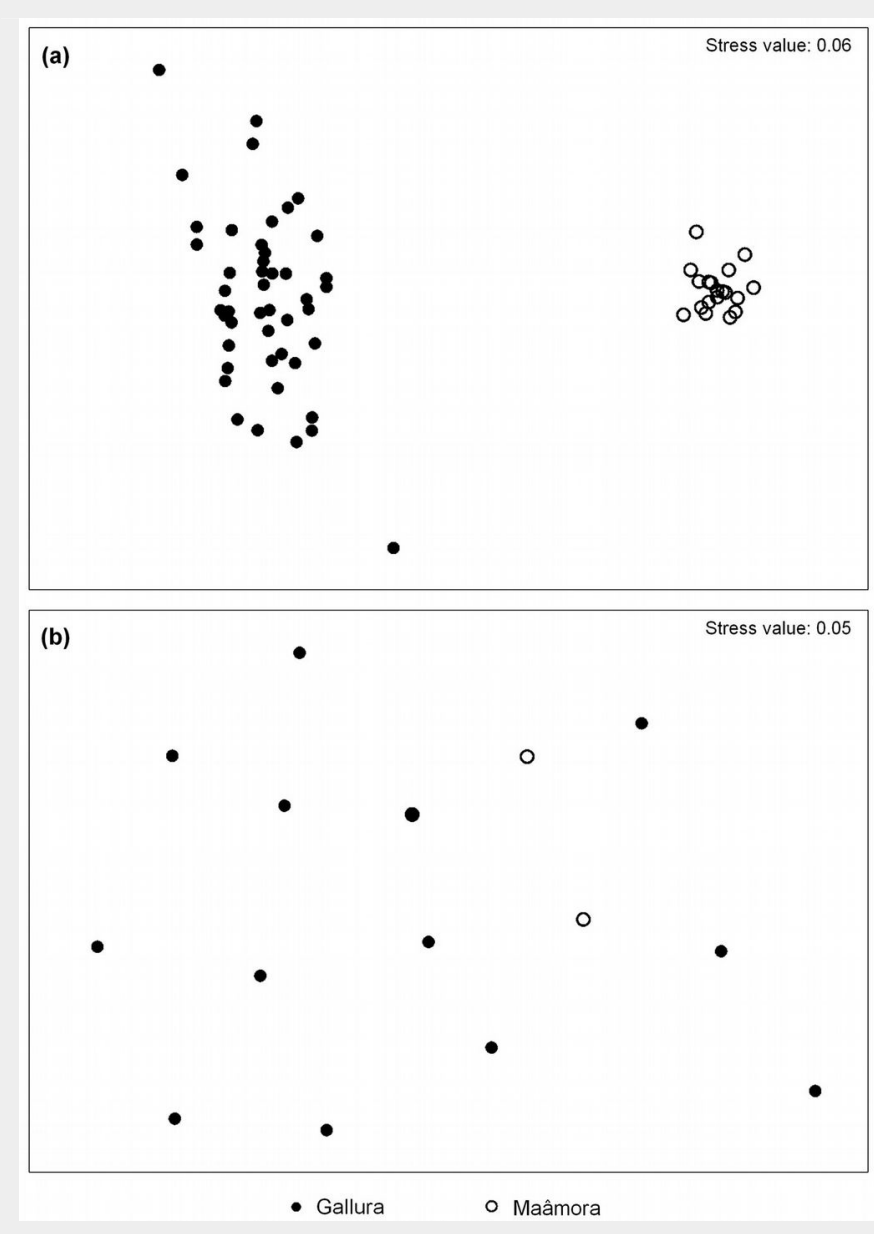

Fig. 2 - Non-Metrical Multidimensional Scaling of samples based on ant occurrence at (a) species and (b) functional group levels. Each circle represents the assemblage of ants caught in a given trap throughout the entire monitoring season.

Tab. 3 - SIMPER test based on functional groups (see Tab. 2 for group acronyms). Comparison and percentage contribution to average Bray-Curtis dissimilarity between districts at different spatial scales. (SD): standard deviation.

\begin{tabular}{llcccc}
\hline $\begin{array}{l}\text { Spatial } \\
\text { scale }\end{array}$ & $\begin{array}{l}\text { Functional } \\
\text { groups }\end{array}$ & $\begin{array}{c}\text { Average } \\
\text { dissimilarity }\end{array}$ & $\begin{array}{c}\text { Dissimilarity } \\
\text { (SD) }\end{array}$ & $\begin{array}{c}\text { Contribution } \\
\text { (\%) }\end{array}$ & $\begin{array}{c}\text { Cumulative } \\
\text { (\%) }\end{array}$ \\
\hline Trap & HC & 6.56 & 1.40 & 40.26 & 40.26 \\
& CC & 5.06 & 0.99 & 31.02 & 71.28 \\
& SC & 1.37 & 0.38 & 8.43 & 79.71 \\
& GM & 1.37 & 0.38 & 8.43 & 88.14 \\
& Cr & 1.70 & 0.42 & 10.42 & 98.56 \\
& Op & 0.24 & 0.15 & 1.45 & 100.00 \\
\hline Site & HC & 6.45 & 3.18 & 44.27 & 44.27 \\
& CC & 4.46 & 2.30 & 30.59 & 74.87 \\
& SC & 1.23 & 1.19 & 8.46 & 83.33 \\
& GM & 1.21 & 0.86 & 8.29 & 91.60 \\
& Cr & 1.01 & 1.19 & 6.95 & 98.57 \\
& Op & 0.21 & 0.44 & 1.43 & 100.00 \\
\hline
\end{tabular}

Tab. 4 - Values of beta diversity and its separated components estimated as average Bray-Curtis dissimilarities $\left(d_{B C}\right)$, balanced variation in species/functional group occurrence $\left(\mathrm{d}_{\mathrm{BC} \text {-bal }}\right)$ and species/functional group gradient $\left(\mathrm{d}_{\mathrm{BC} \text {-gra }}\right)$, respectively. For each component, the relative contribution to the average Bray-Curtis dissimilarities (percentage of $d_{B C}$ ) is also reported in brackets.

\begin{tabular}{llllll}
\hline \multirow{2}{*}{ Grouping } & Beta & Gallura & \multicolumn{3}{l}{ Maâmora } \\
\cline { 3 - 6 } & diversity & Trap & Site & Trap & Site \\
\hline Species & $\mathrm{d}_{\mathrm{BC}}$ & 0.418 & 0.292 & 0.066 & 0.045 \\
& $\mathrm{~d}_{\mathrm{BC} \text {-bal }}$ & $0.304(72.78)$ & $0.227(77.64)$ & $0.014(21.54)$ & $0.022(48.63)$ \\
& $\mathrm{d}_{\mathrm{BC} \text {-gra }}$ & $0.114(27.22)$ & $0.065(22.36)$ & $0.052(78.46)$ & $0.023(51.37)$ \\
Functional & $\mathrm{d}_{\mathrm{BC}}$ & 0.187 & 0.101 & 0.026 & 0.018 \\
groups & $\mathrm{d}_{\mathrm{BC} \text {-bal }}$ & $0.092(49.17)$ & $0.060(59.79)$ & $0.000(0)$ & $0.001(8.11)$ \\
& $\mathrm{d}_{\mathrm{BC} \text {-gra }}$ & $0.095(50.83)$ & $0.041(40.21)$ & $0.026(100.0)$ & $0.016(91.89)$ \\
\hline
\end{tabular}


However, both their historical land use and the intensity of exploitation are very different. In Gallura, the cork oak forest is com prised of uneven aged trees and the grass under the forest is still occasionally grazed. The cork is harvested manually every $10-11$ years and strict rules regulate its exploitation. Despite an appreciable improvement in management practices, the Maâmora forest has deteriorated greatly and the integral conservation of some areas has recently been established in order to promote natural regeneration. The most recent project (Projet de rehabilitation de la Maâmora, 2005-2014) was funded with ap proximately 25 million euros. A new management plan for the next decade (20152024) is being established. However, apart from the cork harvest, the other forest resources (i.e., wood, charcoal, tannin, aromatic and medicinal plants, and acorn harvesting) are still being exploited inappropriately (Fennane \& Rejdali 2015).

The comparison of the ant community composition between the two districts provided new insights into the sensitivity of ants as bioindicators. The species richness observed in the Gallura district was comparable to those found in other Mediterranean oak woodlands (Gómez et al. 2003 Castracani et al. 2010, Satta et al. 2012) Similarly, the species richness detected in Maâmora forest was very close to the results of a previous study based on a different sampling method (Bernard 1970). Lower values of species richness were measured for the Gallura district at both trap and site scales. The mean species rich ness was significantly higher in Maâmora than in Gallura at both the trap and site scales. However, the overall species richness was higher in Gallura than in Maâmora. We attribute these scale-dependent differences to the higher environmental heterogeneity in Gallura, which positively influenced beta diversity.

As expected, the ant fauna from the cork oak woodlands of Morocco and Italy showed very notable differences at the species level. Considering exclusively the five species shared between the two districts, no differences were detected for $C$. scutellaris, the main arboreal species which is noxious to cork oak (Villemant \& Fraval 1993, Verdinelli et al. 2012). In contrast, $P$. pallidula, which is characterized by an efficient mass recruitment system (Cerdá et al. 1998), and T. simrothi, a species very common in various agroecosystems (Bernard 1978, Cerdá et al. 1998, Verdinelli et al. 2007, Lentini \& Verdinelli 2012), had a higher frequency in Maâmora than in Gallura. In addition, C. truncatus, an arborea species associated with deadwood in cork oak woodlands (Villemant \& Fraval 1993), was common in Maâmora and contributed greatly to the Bray-Curtis average dissimilarity between districts. A. spinosa, collected in Gallura, and A. senilis, collected in Maâmora, but also common in the south of Sardinia (Verdinelli et al. 2007), are ecologi- cally close ruderal species which significantly contributed to the differences in assemblage composition between the two districts. At all Maâmora sites, C. viatica and Monomorium subopacum were captured by all the traps used during the survey. These are very common species in the endemic Moroccan Argan forest (El Keroumi et al. 2012), as well as in the urban areas of Rabat, Kenitra and Fès, and in the most degraded areas of Maâmora (Bernard 1970).

Two functional groups, Opportunists and Hot Climate Specialists, which were very common in Gallura and Maâmora, respectively, appeared to control the structure and dynamics of open cork oak woodland ant assemblages through their aggressive behavior and monopolization of resources under thermal stress (Cerdá et al. 1998). The relative contribution of Hot Climate Specialists in Maâmora might be related to the dry conditions of the habitat (Azcarate \& Peco 2012). In contrast, when the presence of these groups was reduced (e.g., by decreased insolation at ground level in the woodlands of Gallura, where a higher canopy cover was measured), Cryptic Species increased their relative frequency. This thermal effect might have been particularly intense and amplified in Maâmora, where the canopy cover is low and the soil is mainly sandy and has a very low organic matter content (Aafi et al. 2005). According to the literature, Hot-Climate Specialists are also abundant in Maâmora, as a likely result of the combination of soil type and vegetation cover, which constitute the main determining factors of ant assemblages (Bestelmeyer \& Wiens 2001, Ríos-Casanova et al. 2006). Although we were not able to identify the drivers of spatial variation in the community composition in depth, the lack of significant differences in ant assemblages within the Maâmora district could be related to environmental and management factors.

In order to clarify this point, the Bray-Curtis index of dissimilarity was partitioned into the two separate components of spatial turnover and nestedness. In Gallura, dissimilarities were principally caused by the relative contribution of turnover, whereas the component with the highest contribution to general dissimilarity in Maâmora was nestedness. In Maâmora, the low values of dissimilarity among sites and the higher contribution of nestedness in the Bray-Curtis dissimilarities could be the consequence of a higher environmental homogeneity. Although the complexity and heterogeneity of the cork oak woodlands could have affected the efficiency of pitfall traps and the catchability of the different species (Melbourne 1999), significant differences in the composition of ant assemblages were detected within the Gallura district at the species level.

The same trend was not observed in Maâmora where the low dissimilarity in ant composition among sites might be related to the general environmental homogeneity of the forest (Nafaa 2002). This highlights the importance of maintaining the diversity in cork oak woodlands and mitigating the large-scale impacts of forest overexploitation. Sustainable ecosystems should be a major conservation objective, especially for fragmented landscapes with multiple landuses. In terms of sustainable forest management, moderate stocking rates, the establishment of temporary grazing-excluded areas and/or of nature reserves could promote plant and animal biodiversity. A longer-term cycle of cork extraction would facilitate the protection of the trees in the most exploited areas. In addition, cork harvesting should be avoided in areas where heavy defoliation, above all by lepidopteran pests, periodically occurs.

In this scenario, a well-managed cork oak system could have strategic importance, not only in terms of soil conservation and the wide array of environmental services it provides, but also for its crucial role in preserving biodiversity (Cruz \& Barata 2011). In fact, in the Gallura cork oak district, livestock breeding, agriculture and forestry coexist, despite the highly fragmented land ownership and the different management practises of the owners.

\section{Conclusions}

Our results highlighted the potential value of ants as bioindicators and their sensitivity to environmental changes in cork oak woodlands. The sampling method we employed enabled to collect mainly grounddwelling and epigeic species. Despite this limitation, pitfall traps also allowed to collect several species associated with the canopy layer, which showed how abundant they are in cork oak woodlands. However, it is possible that other sampling methods and/or multilayer sampling aimed at exploring different microhabitats would better describe the ant assemblages of open woodlands. The results reported by Hoffmann (2010) show that disturbance factors might have a secondary impact on ant assemblages, inducing changes restricted to species composition, but not necessarily affecting overall species richness or abundance.

Our results support the idea that the understanding of beta diversity and its underlying processes at multiple scales is therefore necessary, above all, for the management and conservation of biodiversity in cork oak woodlands. Functional groups showed a lower sensitivity than species in detecting differences between ant assemblages in Gallura and Maâmora. In addition, our results show that more detailed analyses of ant community dynamics are needed in order to improve the predictive power of the functional group approach. Accordingly, an in-depth understanding of the mechanism modelling the ant assemblages in response to different levels of exploitation is very important. In the Maâmora forest, where the widespread human impact 
has been well documented, the long-term monitoring of ants might be very useful in evaluating the effectiveness of the natural forest recovery measures that have been applied in recent years. Agroforestry management systems have been proven to be good predictors of cork oak mortality (Costa et al. 2010). A detailed knowledge of responses of the ant community to human disturbance could improve the accuracy of predictive models aimed at understanding environmental issues, such as the Mediterranean cork oak decline, which have principally been caused by severe exploitation.

\section{Acknowledgements}

This research was funded by the Italian National Research Council and the CNRST (Agreement on Scientific and Technological Cooperation between the National Research Council of Italy and the Centre National pour la Recherche Scientifique et Technique of Morocco 2010-2011), and partially supported by the Autonomous Region of Sardinia (L.R. n. 7/2007, budget 2010-CRP 24480, budget 2013-CRP 7727).

\section{References}

Aafi A, Achhal El Kadmiri A, Benabid A, Rochdi M (2005). Richesse et diversité floristique de la suberaie de la Mamora (Maroc) [Floral richness and diversity of Maâmora cork oak forest (Morocco)]. Acta Botanica Malacitana 30: 127138. [in French] [online] URL: http://cat.inist.fr/? aModele=afficheN\&cpsidt $=17447197$

Andersen AN (1995). A classification of Australian ant communities based on functional groups which parallel plant life-forms in relation to stress and disturbance. Journal of Biogeography 22: 15-29. - doi: 10.2307/2846070 Andersen AN, Hoffmann BD, Müller WJ, Griffiths $A D$ (2002). Using ants as bioindicators in land management: simplifying assessment of ant community responses. Journal of Applied Ecology 39: 8-17. - doi: 10.1046/j.1365-2664.2002.007 04.x

Andersen AN, Majer JD (2004). Ants show the way Down-Under: invertebrates as bioindicators in land management. Frontiers in Ecology and the Environment 2: 291-298. - doi: 10.1890/ 1540-9295(2004)002[0292:ASTWDU]2.0.CO;2

Anderson MJ, Crist TO, Chase JM, Vellend $M$, Inouye BD, Freestone AL, Sanders NJ, Cornell HV, Comita LS, Davies KF, Harrison SP, Kraft NJ, Stegen JC, Swenson NG (2011). Navigating the multiple meanings of $\beta$ diversity: a roadmap for the practicing ecologist. Ecology Letters 14: 1928. - doi: 10.1111/j.1461-0248.2010.01552.x

AntWiki (2016). Home page. Web site. [online] URL: http://www.antwiki.org

Aronson J, Pereira JS, Pausas JG (2009). Cork oak woodlands on the edge: conservation, adaptive management, and restoration. Island Press, Washington, DC, USA, pp. 315.

Azcarate FM, Peco B (2012). Abandonment of grazing in a Mediterranean grassland area: consequences for ant assemblages. Insect Conservation and Diversity 5: 279-288. - doi: 10.1111/j.17 52-4598.2011.00165.x

Baselga A (2013). Separating the two components of abundance-based dissimilarity: bal- anced changes in abundance vs. abundance gradients. Methods in Ecology and Evolution 4: 552-557. - doi: 10.1111/2041-210X.12029

Baselga A, Orme CDL (2012). "betapart": an R package for the study of beta diversity. Methods in Ecology and Evolution 3: 808-812. - doi: 10.1111/j.2041-210X.2012.00224.x

Bernard F (1970). Les fourmis de la forêt de Maâmora (Maroc) [The ants of Maâmora forest (Morocco)]. Revue d'Écologie et de Biologie du Sol 6: 483-513. [In French]

Bernard F (1978). Contribution à la connaissance du Tapinoma simrothi Krausse, fourmi la plus nuisibles aux cultures du Maghreb [Contributions to the knowledge of Tapinoma simrothi Krausse, the most harmful ant in Maghreb crops]. Bulletin de la Société d'Histoire Naturelle de l'Afrique du Nord 67: 87-101. [in French]

Besacier C, Gallo Granizo C (2014). Exploring REDD+ opportunities in the Mediterranean - A regional project funded by the French Global Environment Facility (FFEM). Unasylva 65: 5659.

Bestelmeyer BT, Wiens JA (1996). The effects of land use on the structure of ground-foraging ant communities in the Argentine chaco. Ecological Applications 6: 1225-1240. - doi: 10.2307/ 2269603

Bestelmeyer BT, Wiens K (2001). Ant biodiversity in semiarid landscape mosaics: the consequences of grazing vs. natural heterogeneity. Ecological Applications 11: 1123-1140. - doi: 10.18 90/1051-0761(2001)011[1123:ABISLM]2.0.CO;2

Boudy P (1950). Économie forestière Nord-Africaine, Tome II, Fascicule I, Monographies et traitements des espèces forestières : le chêneliège. [Forest Economics of North Africa, Volume II, Fascicule I, Monographs and Treatments of Forest Species: the Cork oak]. Edition Larose, Paris, France, pp. 249. [in French]

Bugalho MN, Caldeira MC, Pereira JS, Aronson J, Pausas JG (2011). Mediterranean cork oak savannas require human use to sustain biodiversity and ecosystem services. Frontiers in Ecology and the Environment 9: 278-286. - doi: $10.1890 / 100084$

Cammell ME, Way MJ, Paiva MR (1996). Diversity and structure of ant communities associated with oak, pine, eucalyptus and arable habitats in Portugal. Insectes Sociaux 43: 37-46. - doi: 10.1007/BF01253954

Castracani C, Mori A (2006). The role of permanent grasslands on ant community structure: Ants (Hymenoptera: Formicidae) as ecological indicators in the agro-ecosystems of the Taro River Regional Park (Italy). Myrmecological News 9: 47-54. [online] URL: http://www.re searchgate.net/publication/253937130

Castracani C, Grasso DA, Fanfani A, Mori A (2010). The ant fauna of Castelporziano Presidential Reserve (Rome, Italy) as a model for the analysis of ant community structure in relation to environmental variation in Mediterranean ecosystems. Journal of Insect Conservation 14: 585-594. - doi: 10.1007/s10841-010-92853

Cerdá X, Retana J, Cros S (1998). Critical thermal limits in Mediterranean ant species: trade-off between mortality risk and foraging performance. Functional Ecology 12: 45-55. - doi: 10.10 46/j.1365-2435.1998.00160.x
Clarke KR, Gorley RN (2006). PRIMER v6. - User manual/tutorial. PRIMER-E Ltd, Plymouth, MA, USA, pp. 192.

Colwell RK (2006). EstimateS: statistical estimation of species richness and shared species from samples. Version 8.2.0 user's guide and application persistent. Web site. [online] URL: http://purl.oclc.org/estimates

Costa A, Pereira H, Madeira M (2010). Analysis of spatial patterns of oak decline in cork oak woodlands in Mediterranean conditions. Annals of Forest Science 67: 204. - doi: 10.1051/for est/2009097

Costantini EA, L'Abate G, Barbetti R, Fantappiè M, Lorenzetti R, Magini S (2012). Carta dei suoli d'Italia, scala 1:1.000.000 [Soil map of Italy, Scale 1:1.000.000]. Consiglio per la ricerca e la sperimentazione in agricoltura, S.EL.CA, Firenze, Italy. [In Italian]

Cruz L, Barata E (2011). How to make cork oak forest services visible? Environmental Economics 2: 69-79.

Dewitte O, Jones A, Spaargaren O, BreuningMadsen H, Brossard M, Dampha A, Deckers J, Gallali T, Hallett S, Jones R, Kilasara M, Le Roux $\mathrm{P}$, Michéli E, Montanarella L, Thiombiano L, Van Ranst E, Yemefack M, Zougmore R (2013). Harmonisation of the soil map of Africa at the continental scale. Geoderma 211-212: 138-153. - doi: 10.1016/j.geoderma.2013.07.007

El Keroumi A, Naamani K, Soummane H, Dahbi A (2012). Seasonal dynamics of ant community structure in the Moroccan Argan Forest. Journal of Insect Science 12 (94): 1-19. - doi: 10.1673/ 031.012.9401

Ellison AM (2012). Out of Oz: opportunities and challenges for using ants (Hymenoptera: Formicidae) as biological indicators in north-temperate cold biomes. Myrmecological News 17: 105119. [online] URL: http://dash.harvard.edu/han dle/1/8519155

Fennane M, Rejdali M (2015). The world largest cork oak Maamora forest: challenges and the way ahead. Flora Mediterranea 25: 277-285. [online] URL: http://www.herbmedit.org/flo ra/FL25SI_277-286.pdf

Fisher J, Beames L, Rangers BJ, Rangers NN, Majer J, Heterick B (2014). Using ants to monitor changes within and surrounding the endangered Monsoon Vine Thickets of the tropical Dampier Peninsula, north Western Australia. Forest Ecology and Management 318: 78-90. doi: 10.1016/j.foreco.2014.01.010

Gerlach J, Samways M, Pryke J (2013). Terrestrial invertebrates as bioindicators: an overview of available taxonomic groups. Journal of Insect Conservation 17: 831-850. - doi: 10.1007/s10841013-9565-9

Gómez C, Casellas D, Oliveras J, Bas JM (2003). Structure of ground-foraging ant assemblages in relation to land-use change in the northwestern Mediterranean region. Biodiversity and Conservation 12: 2135-2146. - doi: 10.1023/A:1024 142415454

Graham JH, Krzysik AJ, Kovacic DA, Duda JJ, Freeman DC, Emlen JM, Zak JC, Long WR, Wallace MP, Graham CC, Nutter JP, Balbach HE (2009). Species richness, equitability, and abundance of ants in disturbed landscapes. Ecological Indicators 9: 866-877. - doi: 10.1016/j.ecolind. 2008.10.003 
Hoffmann BD (2010). Using ants for rangeland monitoring: global patterns in the responses of ant communities to grazing. Ecological Indicators 10: 105-111. - doi: 10.1016/j.ecolind.2009.04. 016

IUSS Working Group WRB (2007). World reference base for soil resources 2006. First update 2007. World Soil Resources Reports 103, FAO, Rome, Italy, pp. 128.

Lentini A, Verdinelli M (2012). Formicidae. In: “Integrated Control of Citrus Pests in the Mediterranean Region" (Vacante V, Gerson U eds). Bentham Science Publishers Ltd, Saif Zone Sharjah, UAE, pp. 231-241.

Melbourne BA (1999). Bias in the effect of habitat structure on pitfall traps: an experimental evaluation. Australian Journal of Ecology 24: 228-239. - doi: 10.1046/i.1442-9993.1999.00967.x Nafaa R (2002). Dynamique du milieu naturel de la Mamora. Paléoenvironnements et évolution actuelle de la surface [Dynamic of the natural environment of the Maâmora. Paleo-environments and current evolution of the area]. PhD thesis, Université Hassan II, Mohammedia, Rabat, Morocco, pp. 321. [In French]

Ottonetti L, Tucci L, Santini G (2006). Recoloniza- tion patterns of ants in a rehabilitated lignite mine in central Italy: potential for the use of Mediterranean ants as indicator of restoration processes. Restoration Ecology 14: 60-66. - doi: 10.1111/j.1526-100X.2006.00105.X

R Development Core Team (2011). R: a language and environment for statistical computing. $R$ Foundation for Statistical Computing. Vienna, Austria, pp. 3551. [online] URL: http://www.rproject.org

Ríos-Casanova L, Valiente-Banuet A, Rico-Gray V (2006). Ant diversity and its relationship with vegetation and soil factors in an alluvial fan of the Tehuacán Valley, Mexico. Acta Oecologica 29: 316-323. - doi: 10.1016/j.actao.2005.12.001 Rossetti I, Bagella S (2014). Mediterranean Quercus suber wooded grasslands risk disappearance: new evidences from Sardinia (Italy). Forest Ecology and Management 329: 148-157. doi: 10.1016/j.foreco.2014.06.010

Satta A, Verdinelli M, Ruiu L, Buffa F, Salis S, Sassu A, Floris I (2012). Combination of beehive matrices analysis and ant biodiversity to study heavy metal pollution impact in a post-mining area (Sardinia, Italy). Environmental Science and Pollution Research 19: 3977-3988. - doi: 10.1007/s11356-012-0921-1

Statistical Graphics Corp. (2001). Statgraphics plus 2001: Statgraphics plus user's guide vers. 5. Manugistics Inc., Rockville, MD, USA, pp. 730.

Stewart AM, Edmisten KL, Wells R, Collins GD (2007). Measuring canopy coverage with digital imaging. Communications in Soil Science and Plant Analysis 38: 895-902. - doi: 10.1080/0010 3620701277718

Verdinelli M, Sassu A, Molinu A, Fois X (2007). An updated list of Sardinian's ants (Hymenoptera Formicidae). Redia 90: 61-66.

Verdinelli M, Loi A, Luciano P (2012). Ant species noxious to cork oak in Sardinia. IOBC/WPRS Bulletin 76: 249-252.

Villemant C, Fraval A (1993). La faune entomologique du chêne-liège en forêt de la Maâmora (Maroc) [The insect fauna of the cork-oak tree in the Mamora forest (Morocco)]. Ecologia Mediterranea 19: 89-98. [in French]

Warwick RM, Clarke KR, Suharsono (1990). A statistical analysis of coral community responses to the 1982-83 El Niño in the Thousand Islands, Indonesia. Coral Reefs 8: 171-179. - doi: 10.1007/ BFo0265008 